\title{
Phyllotaxis instability - exploring the depths of first available space
}

\author{
Marcin Szpak, Beata Zagórska-Marek* \\ Institute of Plant Biology, Wrockaw University, Kanonia 6/8, 50-328 Wrockaw, Poland
}

\section{Abstract}

The theoretical analysis of the consequences of the phyllotactic pattern being propagated according to the first available space rule has revealed that all monojugate patterns, with the exception of the main Fibonacci pattern, should become developmentally unstable in their low expressions. This fact explains why the main Fibonacci pattern plays the dominant role among other patterns of spiral phyllotaxis. The probability that the pattern becomes unstable varies for different patterns, which likely makes them more or less frequent, and thus easier or more difficult to encounter in nature. The unstable pattern inevitably transforms into another, as the computer simulations show. Theoretically predicted instability of low order phyllotaxis may be treated as one of the causes of natural ontogenetic transitions, occurring in plants. This, however, still does not explain why in nature some patterns with high order of phyllotaxis also change, quite readily one into the other, in shoot apical meristem's ontogeny.

Keywords: phyllotaxis, phyllotactic transitions, shoot apical meristem, plant ontogeny

\section{Introduction}

The diversity of phyllotactic patterns is best represented by a phyllotactic grid $[1,2]$. The lattice made of orthogonal lines (Fig. 1) resembles an unrolled cylindrical surface of a plant shoot (Fig. 2), where the leaves (or other lateral organs such as flower parts) are positioned at the points of intersection of connecting lines (parastichies).

Theoretically, as the lattice shows, there is an infinite number of possible patterns. Yet, only a few of them have been identified in nature. Some patterns are more frequent than others [3]. The most common is the main Fibonacci pattern with $m: n$ contact parastichy numbers: $1: 2,2: 3,3: 5,5: 8$, etc. The reason for its prevalence is not yet known.

The enigma of the varying frequency of phyllotactic patterns is paralleled by yet another - that of phyllotactic transitions. These are ontogenetic changes in the pattern of lateral organ distribution, which result from the shoot apical meristem's (SAMs) organogenic activity being altered somehow. The question is raised as to why the pattern is changing in plant development? In a previous paper [4], it has been shown, in computer simulations, that this can be explained by changes in the ratio between the size of pattern elements and the size of simulation space. In a geometric model of phyllotaxis implemented in the simulations it was assumed that the formation

\footnotetext{
*Corresponding author. Email: beata@biol.uni.wroc.pl

This is an Open Access digital version of the article distributed under the terms of the Creative Commons Attribution 3.0 License (creativecommons.org/licenses/by/3.0/), which permits redistribution, commercial and non-commercial, provided that the article is properly cited.
}

of the new element in a phyllotactic pattern takes place in the first available space, in the lowest position with respect to the shoot apex summit. This assumption is concordant with the idea proposed by Snow and Snow [5-7] and supported by their experimental data. New developmental studies on SAM activity show that regulation of sizes is on a genetic level [8-11].

The phenomenon of phyllotactic transitions is intriguing. It increases phyllotactic diversity, which can be very high in some plants, as in magnolia flowers [2]. Fluctuations in the sizes of lateral organ primordia affecting the above ratio occur in nature, especially when the identity of the organ changes. The stamen primordia in a magnolia's generative shoot are clearly smaller than initiated later, thus ontogenetically younger, carpel primordia $[2,12,13]$. In Verbena the SAM entering the flowering phase starts producing bract primordia, which are smaller than primordia of the leaves (unpublished data). Also, in Torreya, the primordia of needles are smaller than those of cataphylls [14]. The changes in size of organogenic space are also possible, as this is often seen in dichotomizing shoots of club mosses $[15,16]$ in abphyl mutants of maize $[17,18]$ or in dec mutants of rice [19], where the mutant's apical meristem is much larger than that of the WT plant. However, the proportion between the values of these two parameters is not the only important factor in phyllotactic transitions. Sometimes, there are two equivalent positions for newly forming primordium in organogenic space. The choice of one of them may affect the quality of the emerging pattern differently than the selection of the other. Thus, in a previous paper [4], the ambiguity of the first available space rule has been noted.

In this paper, which further explores the potentials of the "first available space", an analysis was carried out of geometric stability of phyllotactic patterns, both natural and those predicted theoretically from a phyllotactic grid. It appears that some of them are more stable than others when propagated according to the first available space principle. 


\section{Results}

Drawing ideal phyllotactic patterns on the phyllotactic grid (with a formative angle $\alpha$ ) is a common practice. It appears, however, that this intuitively natural representation of the pattern may have consequences far from botanic reality. Even more important is that, in some cases, it collides with the assumptions of the geometric model of phyllotaxis.

\section{Developmental instability of phyllotactic pattern}

Let us take a closer look at the model, used in earlier work [4] in its most simple form, where the circular pattern elements

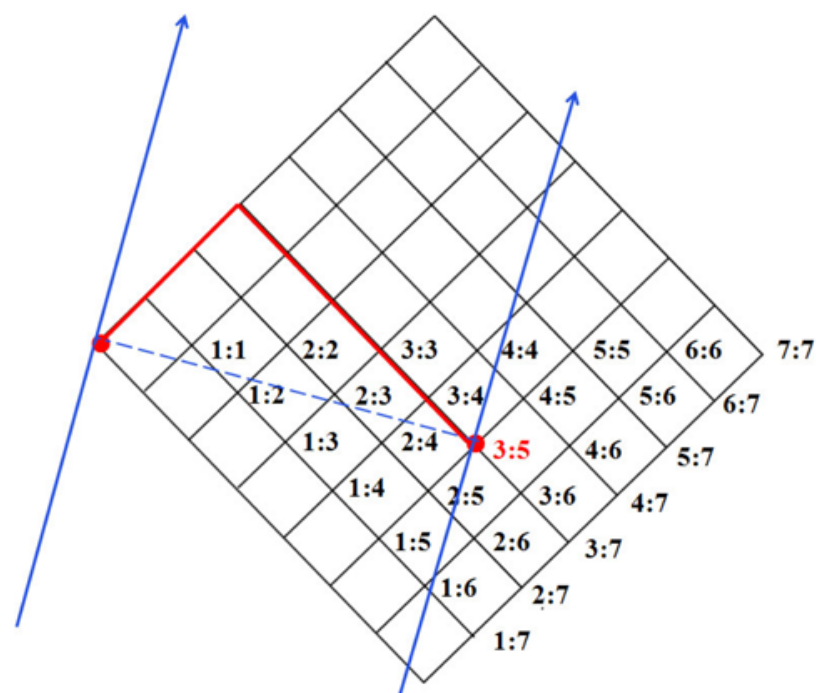

Fig. 1 Schematic view of phyllotactic grid. Identification of the starting point (left red dot) with any other intersection point defines: (i) the circumference of the cylindrical organogenic surface of the plant shoot (broken blue line); (ii) the inclination of the grid to the shoot longitudinal axis (blue arrows); and (iii) phyllotaxis. The latter is indicated by the pair of numbers given at every intersection point. They refer to the $m: n$ numbers of opposite parastichies in a particular pattern. In this case it is a pair of $3 \mathrm{~s}: 5 \mathrm{z}$ parastichies; characteristic for the main Fibonacci pattern ( $\mathrm{s}$ - parastichies inclined to the left; $\mathrm{z}$ - parastichies inclined to the right on the surface of the shoot). The grid may be extrapolated to the right indefinitely. Unlabelled upper part of the grid is a mirror image of the bottom part - the chirality of patterns there is opposite.

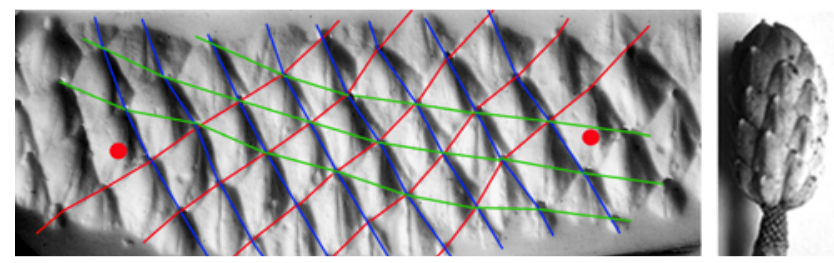

Fig. 2 Clay replica of an unrolled cylindrical surface of a magnolia generative shoot with the main Fibonacci pattern of $3 \mathrm{~s}$ (green): $5 \mathrm{z}$ (red): $8 \mathrm{~s}$ (blue). Chirality of the replicated pattern is a mirror-image of the real one because it is looked at from the inside of the shoot; the same apocarpic ovary (pattern element) reproduced twice on both lateral margins of the replica is marked with red dots; the resemblance of the replica to the crystal lattice and to the phyllotactic grid from Fig. 1 is striking . have the same radial size $(R)$ and where any new pattern element falls into the lowest position on the circumference. Now, let us consider the ideal phyllotactic pattern of 1:4 drawn on the grid (Fig. 3), which means that the parastichies intersect each other at right angles $(\alpha)$.

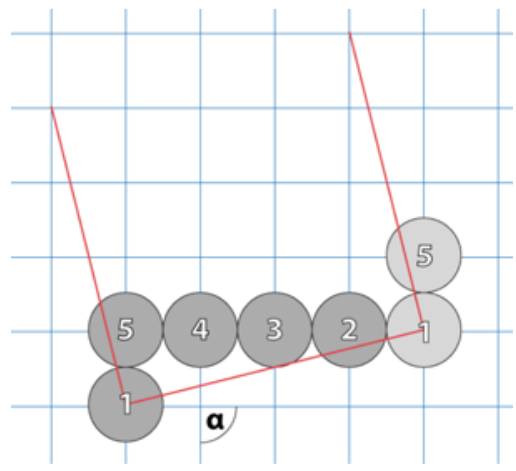

Fig. 3 The ideal 1s:4z phyllotactic pattern drawn on a grid; where $\alpha$ equals 90 degrees; the red frame outlines the size of organogenic space and shows grid orientation with respect to the vertical axis of the plant shoot and to its circumference.

This unusual pattern, although infrequent and thus much less known than the main Fibonacci pattern, may be encountered in magnolia flowers within their exceptionally rich phyllotactic spectrum, but also in other plants such as Abies balsamea [20], Verbena officinalis or Actinidia arguta (Fig. 4, Fig. 5). This has also been selected for the reason that in the expression 4:5 it is geometrically very close to the main Fibonacci 3:5 expression.

Propagation of the initial 1s:4z pattern generated artificially (drawn on the grid), requires, according to the model, that the next pattern element - circle No. 6 - is initiated (added) in the lowest position (Fig. 6). It is immediately apparent that this position ( 6 - above and between 2 and 3 on Fig. 6$)$ is different than the position predicted by the grid (6' on Fig. 6), which would be selected if the pattern were to be propagated in the same form. Evidently this pattern is not stable. Breaking the symmetry is inevitable. The consequences of symmetry breaking, due to the pattern reaching a state of instability, may be observed when the simulation of the initiation process continues (Fig. 7).

\section{General phenomenon and conditions required for state of instability of other defined patterns}

As shown in an earlier paper [4], in a case of the main Fibonacci pattern, a computer simulation of a continuous change in $R$ (either way) may decrease or increase the pattern expression (order) without changing its quality (with one peculiar exception between the 1:2 and 2:3 expressions). All transient states, between consecutive expressions of the pattern, preserve the numbers of conspicuous parastichies typical for a given expression within the range of $\alpha$ values $60-120$. Passing the limiting value of this range changes the numbers of contact parastichies, but these numbers still belong to the Fibonacci series. Even the lowest expression of 1:1 (a distichous pattern) should be treated as an expression of a main Fibonacci pattern, as the series starts with 1:1 numbers. In this case one will never observe the instability just described for a 1:4 pattern.

Therefore, it needs to be asked under what circumstances the phyllotactic pattern becomes unstable? 

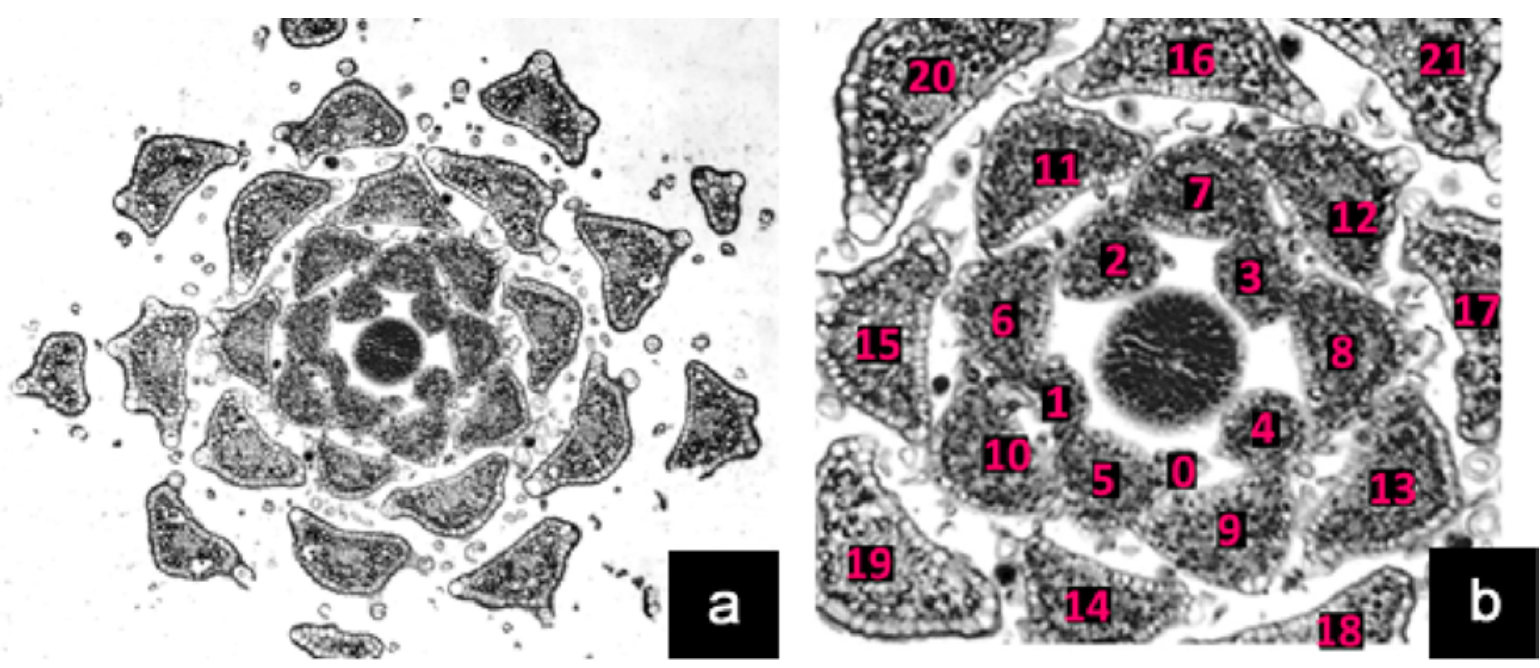

Fig. 4 Verbena officinalis. a Cross-section of the inflorescence's apex; $\mathbf{b}$ Its close-up. There are five bract primordia initiated on one revolution of the z-oriented ontogenetic helix; the phyllotaxis expression is 1z:4s:5z.

After short calculations over $\varphi$ angle (Fig. 8) the following conclusion can be made: for

$$
\frac{\pi}{3} \leq \alpha \leq \frac{2 \pi}{3}
$$

and

$$
x=\frac{m}{n},(m<n)
$$

thus:

(i) the pattern is stable, if

$$
f(x, \alpha)=\frac{\alpha}{2}+\arccos \left(x-\frac{\cos \alpha}{\sqrt{1+x^{2}-2 x \cos \alpha}}\right)-\frac{2}{3 \pi}<0
$$

(ii) it is unstable, if

$$
f(x, \alpha)>0
$$

(iii) in case

$$
f(x, \alpha)=0
$$

the model does not give us a unique solution.

The following will quickly show that the Fibonacci pattern is the only stable pattern in a monojugate pattern sequence. It is clear that

$$
f\left(\frac{1}{2}, \frac{\pi}{3}\right)=0
$$

and both

$$
f\left(x, \frac{\pi}{3}\right)=0
$$

and

$$
f\left(\frac{1}{2}, \alpha\right)=0
$$

are strictly decreasing, as a composition of the monotonic functions. This gives us

$$
f\left(\frac{1}{2}, \alpha\right)<0
$$

for all

$$
\alpha>\frac{\pi}{3}
$$

and

$$
f\left(x, \frac{\pi}{3}\right)>0
$$

for all

$$
x>\frac{1}{2}
$$

and thus proof is provided.
The summary of conditions, in which the patterns are either developmentally stable or unstable is given in Tab. 1 . The most stable is the main Fibonacci pattern, the stability of other patterns gradually decreases with the increase of $n$ relative to $m$.

\section{Discussion}

It is clear that some patterns, even though we can easily and precisely generate them on the grid, cannot be propagated according to the first available space principle. Further build up of the pattern, with the rule strictly observed, results in an inevitable change of the pattern - in phyllotactic transition to another identifiable pattern (Fig. 7) or in the chaotic arrangement of pattern elements, which is difficult to classify. This type of transition does not require a change in $R$. Thus we have come to yet another (aside from changing $R$ ) plausible cause of natural phyllotactic transitions.

However, these transitions are limited to the cases when a given pattern, due to an earlier continuous increase in $R$, reaches its lowest expression. From the empirical data

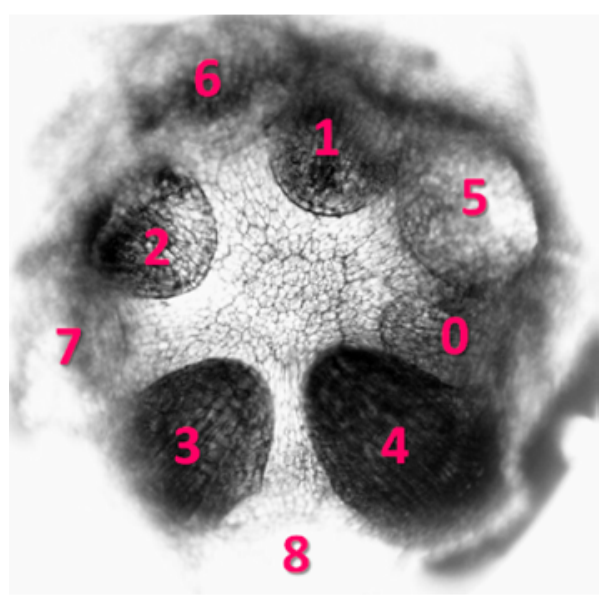

Fig. 5 Actinidia arguta: vegetative apex with five leaf primordia initiated on one revolution of the s-oriented ontogenetic helix; phyllotaxis is expressed here as a 1s:4z:5s parastichy pattern. 


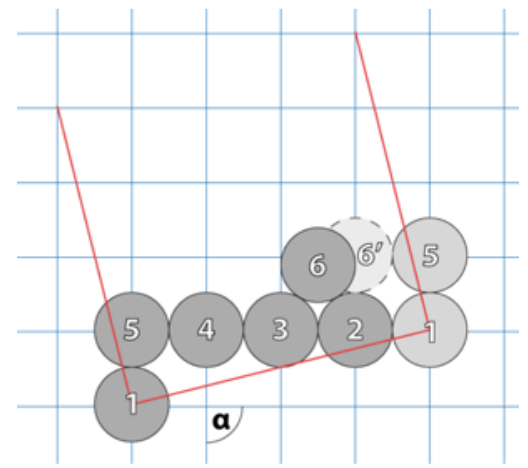

Fig. 6 Further propagation of the $1 \mathrm{~s}: 4 \mathrm{z}$ pattern, the same as that shown in Fig. 3, according to the first available space principle is not possible. Detailed description in text.

accumulated over the past two decades, as a result of extensive research on phyllotaxis of conifers [20-22], club mosses [15,16] magnolias [2] and cacti [23-25], we know that qualitative phyllotactic transitions occurring through dislocations are mainly transitions between patterns with a high order of phyllotaxis. One of the published SEM photographs of magnolia floral apices [2] shows how a 5:9 pattern changes into a 5:8 (Fig. 9). The same transition in another, already mature, floral shoot is shown in Fig. 10.

What causes such instability of the high order phyllotactic pattern is yet to be elucidated.
It is also interesting as to what directs the transition. In nature, the same pattern may transform in many different ways, with many resulting patterns. For instance, the 5:9 pattern may change into to the main Fibonacci $5: 8$, but also into to the trijugate 6:9 phyllotaxis. This is a separate problem to be studied in the future. The preliminary analysis shows that the important factors, recently introduced as options in the computer program, might be: $(i)$ vertical tolerance and (ii) random fluctuations of the $R$ value within a given range.

There is one more important conclusion drawn from the above research, and it pertains to the phenomenon of unequal frequency of natural patterns. In nature, among spiral patterns, the most common initial pattern is the low order main Fibonacci pattern $-1: 2$. It may be said that this is so because $1: 2$ is just a higher expression of the most simple pattern possible - 1:1.

Yet now another argument for the high frequency of the Fibonacci pattern can be offered. As is deduced, this is the only pattern from monojugate patterns, which is always stable for all possible angles $\alpha$. The biological implication of this fact is that all patterns other than Fibonacci patterns, which might rise in the situation of a phyllotaxis' lowest order, should be quickly eliminated in the shoot apex ontogeny. This is done as their transitions, at least in a case of lowering pattern expression, would inevitably lead to the main Fibonacci pattern.

Going further it is proposed that patterns with a low $m: n$ ratio either do not exist in nature or are very infrequent (only for high values of $\alpha$ ). The patterns that do exist in nature are

Tab. 1 A selection of monojugate patterns in $m / n$ descending order.

\begin{tabular}{|c|c|c|c|c|c|c|c|c|c|c|c|c|c|}
\hline & & & 1 & 3 & 2 & 3 & 1 & 2 & 1 & 1 & 1 & 1 & 1 \\
\hline & radians & $n$ & 2 & 7 & 5 & 8 & 3 & 7 & 4 & 5 & 6 & 7 & 8 \\
\hline alpha & & $x=m / n$ & 0.5 & 0.43 & 0.4 & 0.38 & 0.33 & 0.29 & 0.25 & 0.2 & 0.17 & 0.14 & 0.13 \\
\hline 60 & 1.047 & & 0 & 0.08 & 0.11 & 0.14 & 0.19 & 0.24 & 0.28 & 0.33 & 0.37 & 0.39 & 0.41 \\
\hline 63 & 1.1 & & -0.03 & 0.05 & 0.09 & 0.11 & 0.16 & 0.21 & 0.25 & 0.3 & 0.34 & 0.36 & 0.38 \\
\hline 66 & 1.152 & & -0.05 & 0.03 & 0.06 & 0.09 & 0.13 & 0.18 & 0.22 & 0.27 & 0.31 & 0.33 & 0.35 \\
\hline 69 & 1.204 & & -0.07 & 0 & 0.03 & 0.06 & 0.11 & 0.16 & 0.19 & 0.25 & 0.28 & 0.31 & 0.32 \\
\hline 72 & 1.257 & & -0.09 & -0 & 0.01 & 0.04 & 0.08 & 0.13 & 0.17 & 0.22 & 0.25 & 0.28 & 0.3 \\
\hline 75 & 1.309 & & -0.11 & -0 & -0 & 0.01 & 0.05 & 0.1 & 0.14 & 0.19 & 0.23 & 0.25 & 0.27 \\
\hline 78 & 1.361 & & -0.13 & -0.1 & -0 & -0 & 0.03 & 0.08 & 0.11 & 0.17 & 0.2 & 0.22 & 0.24 \\
\hline 81 & 1.414 & & -0.15 & -0.1 & -0.1 & -0 & 0.01 & 0.05 & 0.09 & 0.14 & 0.17 & 0.2 & 0.22 \\
\hline 84 & 1.466 & & -0.17 & -0.1 & -0.1 & -0.1 & -0.02 & 0.03 & 0.06 & 0.11 & 0.15 & 0.17 & 0.19 \\
\hline 87 & 1.518 & & -0.19 & -0.1 & -0.1 & -0.1 & -0.04 & 0.01 & 0.04 & 0.09 & 0.12 & 0.15 & 0.16 \\
\hline 93 & 1.623 & & -0.22 & -0.2 & -0.1 & -0.1 & -0.08 & -0 & -0 & 0.04 & 0.07 & 0.09 & 0.11 \\
\hline 96 & 1.676 & & -0.23 & -0.2 & -0.2 & -0.1 & -0.1 & -0.1 & -0 & 0.02 & 0.05 & 0.07 & 0.09 \\
\hline 99 & 1.728 & & -0.25 & -0.2 & -0.2 & -0.2 & -0.12 & -0.1 & -0.1 & -0 & 0.02 & 0.05 & 0.06 \\
\hline 102 & 1.78 & & -0.26 & -0.2 & -0.2 & -0.2 & -0.14 & -0.1 & -0.1 & -0 & 0 & 0.02 & 0.04 \\
\hline 105 & 1.833 & & -0.27 & -0.2 & -0.2 & -0.2 & -0.16 & -0.1 & -0.1 & -0.1 & -0 & -0 & 0.01 \\
\hline 108 & 1.885 & & -0.29 & -0.2 & -0.2 & -0.2 & -0.18 & -0.1 & -0.1 & -0.1 & -0 & -0 & -0 \\
\hline 111 & 1.937 & & -0.3 & -0.3 & -0.2 & -0.2 & -0.19 & -0.2 & -0.1 & -0.1 & -0.1 & -0 & -0 \\
\hline 114 & 1.99 & & -0.31 & -0.3 & -0.3 & -0.2 & -0.21 & -0.2 & -0.2 & -0.1 & -0.1 & -0.1 & -0.1 \\
\hline 117 & 2.042 & & -0.32 & -0.3 & -0.3 & -0.3 & -0.23 & -0.2 & -0.2 & -0.1 & -0.1 & -0.1 & -0.1 \\
\hline 120 & 2.094 & & -0.33 & -0.3 & -0.3 & -0.3 & -0.24 & -0.2 & -0.2 & -0.2 & -0.1 & -0.1 & -0.1 \\
\hline
\end{tabular}

Stable patterns - white, unstable - pink. It can be seen that for low $m: n$ values there are only a few stable patterns within the 60-120 range of $\alpha$ values, while all variants of a Fibonacci pattern $(m=1, n=2)$ within this range are stable. A 1:4 pattern is stable for less than half of the possible angles of $\alpha$. Even the 9:19 pattern with a high $m: n$ proportion (close to 1/2) is unstable for some $\alpha$. 

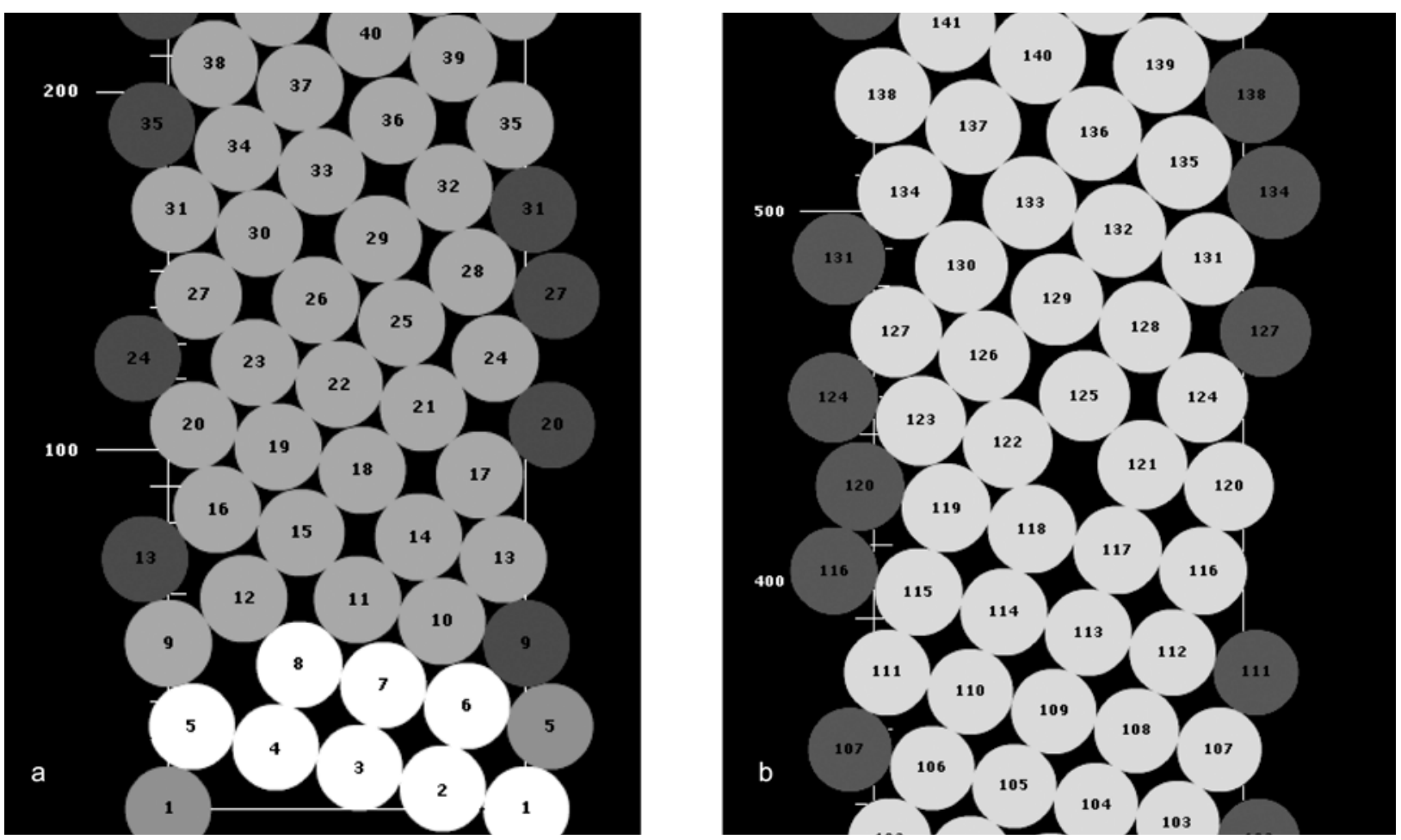

Fig. 7 A computer simulation of the consequences of the 1:4 pattern's instability. a The first 8 elements of the initial 1s:4z pattern are placed arbitrarily on the orthogonal lattice; placement of the 9th element in the lowest position required by the model, changes the initial pattern into a pattern hard to classify equivocally of $1 \mathrm{~s}: 3 \mathrm{z}: 4 \mathrm{~s}$ or $2 \mathrm{~s}: 3 \mathrm{z}: 5 \mathrm{~s}$; here $R$ (the size of pattern elements) is constant; in nature the situation shown in a may develop spontaneously as a result of a continuous increase in $R$, as shown in $\mathbf{b}$. $\mathbf{b}$ The initial 5:4 pattern changes its expression into 1:4 due to the earlier continuous increase in $R$ by $0.4 \%$; it thus reaches a point of instability (as in Fig. 6 ), in the area where an almost orthogonal phyllotactic lattice emerges (see circles No. 116, 117, 120, and 121). After this transient moment the next pattern element (No. 122) appears between circles No. 118 and No 119, instead of being initiated above circle No. 118. This position is the first available. It is lower than that above circle No. 118, which would guarantee propagation of an unaltered 1:4 pattern. As a result, the 1:4 pattern transforms into a 1:3 - which is an imperfect but clear enough Lucas pattern (here $R$ still rises continuously above the symmetry breaking point).

those with a high $m: n$ ratio and must be generated within the range of angles that guarantees pattern stability. This plausible hypothesis seems to have some support in empirical observations of pattern frequency. The patterns with such a high $m: n$ ratio, i.e. 1:2 (Fibonacci) and 1:3 (Lucas) are quite frequent according to biological observations.

The advantage of in silico experiments and theoretical analysis is that very quickly, through simulations, we may indentify the principles that lay behind natural phyllotactic
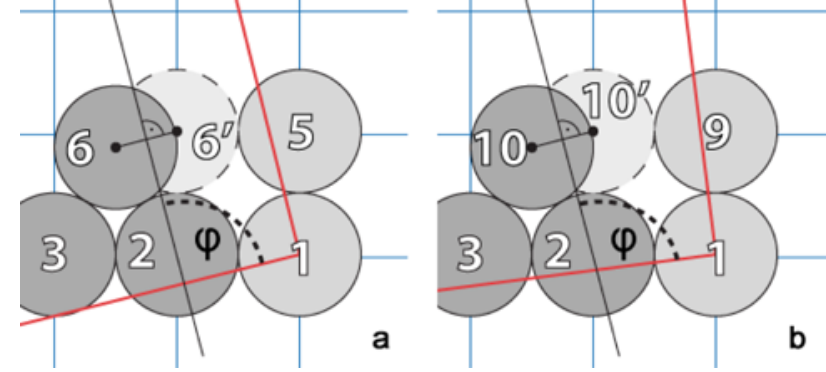

Fig. $8 \Phi$ angle and pattern stability. a If $\varphi>\pi / 2$ then the pattern is unstable [because a new circle (6) "drops" from the grid position into the lowest position - between 2 and 3], if $\varphi<\pi / 2$ it is stable. In case $\varphi$ $=\pi / 2$, then both the (6) and (6) positions are equivalent (in the first available space). $\mathbf{b}$ An artificial 1:8 pattern drawn for a better view of new circle (10) "dropping". It's clear that here $\varphi>\pi / 2$. transitions and phyllotactic diversity. It is surprising how well the simplest geometric model of phyllotaxis explains all these phenomena.

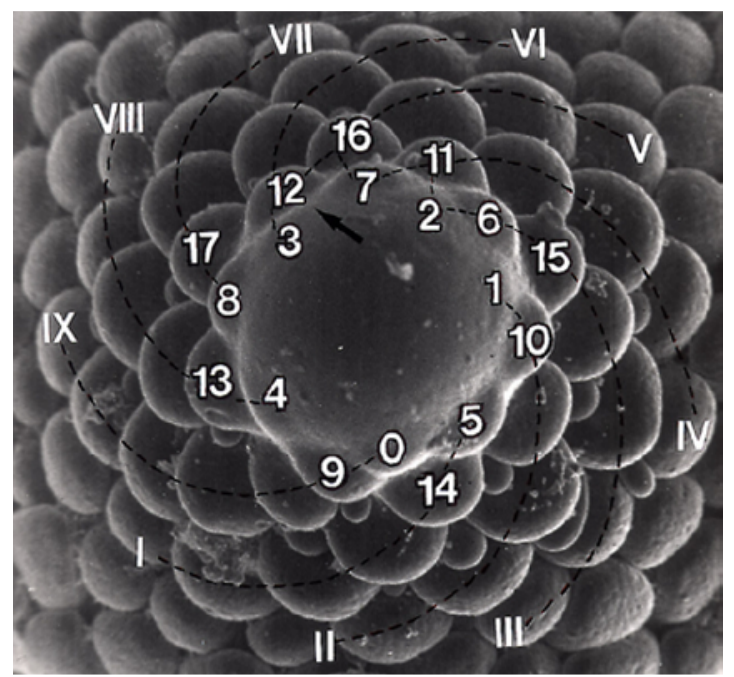

Fig. 9 Scanning electron microscope picture showing the resin cast of a magnolia floral apex with phyllotactic transition from a $5 \mathrm{~s}: 9 \mathrm{z}$ to $5 \mathrm{~s}: 8 \mathrm{z}$ parastichy pattern; one of originally nine parastichies, labeled with roman numerals, ends its course in the upper part of the apex circumference (black arrow); slightly modified from [2], with permission. 


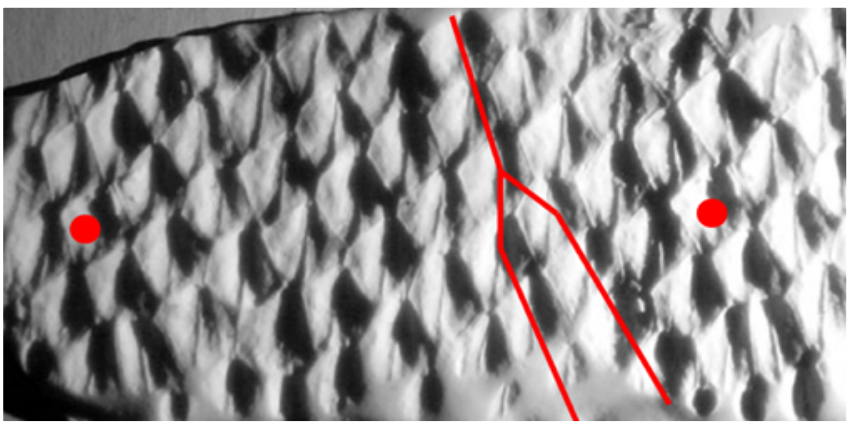

Fig. 10 Clay replica of an unrolled cylindrical surface of a magnolia's generative shoot with the pattern $5 z: 9$ s changing developmentally into $5 z: 8 s$ through one dislocation (two parastichies uniting shown with red lines); this is the same transition as that shown in Fig. 9, bearing in mind the chirality of replicated pattern and its mirror image in the replica; the red dots show the same marker of the organogenic surface - the apocarpic ovary (pattern element), replicated twice on both lateral margins of the replica.

\section{Acknowledgements}

The authors wish to thank Mrs. Magdalena Turzańska (M.Sc.) for her outstanding work in preparing shoot apices for microscopic observations. This work was financially supported by the grant of Polish Ministry of Science and Higher Education N303 096834.

\section{References}

1. Zagórska-Marek B. Phyllotaxis triangular unit: phyllotactic transitions as the consequence of apical wedge disclinations in a crystal-like pattern of the units. Acta Soc Bot Pol. 1987;56(2):229-255.

2. Zagórska-Marek B. Phyllotaxic diversity in Magnolia flowers. Acta Soc Bot Pol. 1994;63(2):117-137.

3. Jean R. Phyllotaxis: a systematic study in plant morphogenesis. Cambridge: Cambridge University Press; 1994. http:// dx.doi.org/10.1017/CBO9780511666933

4. Zagórska-Marek B, Szpak M. Virtual phyllotaxis and real plant model cases. Funct Plant Biol. 2008;35(10):10251033. http://dx.doi.org/10.1071/FP08076

5. Snow M, Snow R. Experiments on phyllotaxis. I. the effect of isolating a primordium. Phil Trans. 1931;221B:1-43.

6. Snow M, Snow R. Minimum areas and leaf determination. Proc R Soc B. 1952;139(897):545-566. http://dx.doi. org/10.1098/rspb.1952.0034

7. Snow M, Snow R. A theory of the regulation of phyllotaxis based on Lupinus albus. Phil Trans. 1962;244B(717):483-513.

8. Clark SE, Williams RW, Meyerowitz EM. The CLAVATA1 gene encodes a putative receptor kinase that controls shoot and floral meristem size in Arabidopsis. Cell. 1997;89(4):575-585. http://dx.doi.org/10.1016/ S0092-8674(00)80239-1
9. Chuang CF, Running MP, Williams RW, Meyerowitz EM. The PERIANTHIA gene encodes a bZIP protein involved in the determination of floral organ number in Arabidopsis thaliana. Gene Dev. 1999;13(3):334-344. http://dx.doi. org/10.1101/gad.13.3.334

10. Schoof H, Lenhard M, Haecker A, Mayer KF, Jürgens G, Laux T. The stem cell population of Arabidopsis shoot meristems in maintained by a regulatory loop between the CLAVATA and WUSCHEL genes. Cell. 2000;100(6):635644. http://dx.doi.org/10.1016/S0092-8674(00)80700-X

11. Reddy GV, Meyerowitz EM. Stem-cell homeostasis and growth dynamics can be uncoupled in the Arabidopsis shoot apex. Science. 2005;310(5748):663-667. http://dx.doi. org/10.1126/science.1116261

12. Xu F, Rudall PJ. Comparative floral anatomy and ontogeny in Magnoliaceae. Plant Syst Evol. 2006;258(1-2):1-15. http://dx.doi.org/10.1007/s00606-005-0361-1

13. Wiss D. Zmienność cech wzorów filotaktycznych w pędach generatywnych Magnolia [PhD thesis]. Wrocław: Wrocław University; 2008.

14. Banasiak A, Zagórska-Marek B. Signals flowing from mature tissues to SAM determine the phyllotactic continuity in successive annual increments of the conifer shoot. Acta Soc Bot Pol. 2006;75(2):113-121.

15. Gola EM. Phyllotaxis diversity in Lycopodium clavatum L. and Lycopodium annotinum L. Acta Soc Bot Pol. 1996;65(3-4):235-247.

16. Gola EM. Morfogenetyczne efekty dychotomizacji pędu widłaków Lycopodium annotinum L. i Lycopodium clavatum L. [PhD thesis]. Wrocław: Wrocław University; 1999.

17. Greyson RI, Walden DB. The ABPHYL syndrome in Zea mays. I. Arrangement, number and size of leaves. Am J Bot. 1972;59(5):466-472. http://dx.doi.org/10.2307/2441527

18. Greyson RI, Walden DB, Hume JA, Erickson RO. The ABPHYL syndrome in Zea mays. II. Patterns of leaf initiation and the shape of the shoot meristem. Can J Bot. 1978;56(13):1545-1550. http://dx.doi.org/10.1139/b78-183

19. Itoh JI, Nagato Y. A mutation associated with phyllotaxy and leaf blade-sheath boundary in rice. Rice Genet Newsl. 1998;15:90-93.

20. Zagórska-Marek B. Phyllotactic patterns and transitions in Abies balsamea. Can J Bot. 1985;63(10):1844-1854. http:// dx.doi.org/10.1139/b85-259

21. Zagórska-Marek B, Banasiak A. Related to phyllotaxis interlocked systems of vascular sympodia and cortical resin canals in Abies and Picea shoots. Acta Soc Bot Pol. 2000;69(3):165-172.

22. Yin X, Lacroix C, Barabé D. Phyllotactic transitions in seedlings: the case of Thuja occidentalis. Botany. 2011;89(6):387396. http://dx.doi.org/10.1139/b11-027

23. Gola EM. Filotaksja u kaktusów, czyli zabawa natury z liczbami. Kaktusy i inne. Cacti and others. 2009;6:4-11.

24. Gola EM. Phyllotactic spectra in cacti: Mammillaria species and some genera from Rebutia group. Acta Soc Bot Pol. 1997;66(3-4):237-257.

25. Gola EM. Phyllotactic pattern formation in early stages of cactus ontogeny. Acta Soc Bot Pol. 2006;75(4):271-279. 